\title{
Mini-Review
}

http://www.jneurovirol.com

\section{The problems of latent varicella zoster virus in human ganglia: precise cell location and viral content}

\author{
Ravi Mahalingam ${ }^{1}$, Peter GE Kennedy ${ }^{3}$ and Donald H Gilden*1,2 \\ ${ }^{1}$ Department of Neurology, University of Colorado, Health Sciences Center, 4200 East Ninth Avenue, Box B-182, Denver, \\ Colorado 80262, USA; ${ }^{2}$ Department of Microbiology, University of Colorado, Health Sciences Center, 4200 East Ninth \\ Avenue, Box B-182, Denver, Colorado 80262, USA; and ${ }^{3}$ University Department of Neurology, Institute of Neurological \\ Sciences, Southern General Hospital NHS Trust, Glasgow G51 4TF, UK
}

Keywords: VZV latency; cell type infected

Varicella zoster virus (VZV) causes chickenpox (varicella) in children, becomes latent in dorsal root ganglia, and reactivates decades later to produce shingles (zoster). Zoster and its neurologic complications are an important cause of morbidity, and occasionally mortality, particularly in the elderly and immunocompromised population. Any attempt to prevent virus reactivation must begin with an understanding of the physical state of virus during latency, not the least of which is identification of the cell type in human ganglia which harbors virus.

Last year, Kennedy et al (1998), using both in situ hybridization (ISH) and PCR-ISH, found latent VZV located predominantly in trigeminal ganglionic neurons from normal humans (Figure 1). The neuronal signal was exclusively nuclear. Originally, using $\left[{ }^{35} \mathrm{~S}\right]$ nick-translated DNA probes spanning the entire VZV genome, Hyman et al (1983) detected VZV RNA by in situ hybridization (ISH) exclusively in the cytoplasm of $0.08-0.3 \%$ of neurons in three of nine latently infected trigeminal ganglia from three of five individuals. Although the faint signal seen after 3 days of exposure to the emulsion could have resulted from nonspecific binding of probe to perinuclear cytoplasmic pigment often seen in neurons of elderly humans, the same authors later reported VZV RNA in three trigeminal ganglia from nine individuals (Tenser and Hyman, 1987). The detection of VZV nucleic acid (probably RNA) in the cytoplasm of latently infected human ganglionic neurons was confirmed when Gilden et al (1987) used a $1.75 \mathrm{~kb},{ }^{32} \mathrm{P}$-labeled riboprobe transcribed from the SalI-P fragment of VZV DNA correspond-

${ }^{*}$ Correspondence: DH Gilden

Received 15 April 1999; revised 5 May 1999; accepted 10 May 1999 ing to VZV gene 63, which after 6 weeks of exposure to emulsion, revealed VZV-specific nucleic acids exclusively in neurons in two of four thoracic ganglia from one subject (Gilden et al, 1987). Since the radiolabeled VZV probe would have bound to DNA or RNA, and grains were seen over the cytoplasm of neurons, the signal most likely reflected VZV RNA. While all three reports agree that VZV was latent exclusively in neurons, there were some conflicting findings. For example, Gilden et al (1987) found VZV in many neurons, in contrast to the rare detection of VZV in neurons reported by Hyman et al (1983) and Tenser and Hyman (1987). While no immediate explanation for the different number of latently infected neurons is obvious, the differences reported could reflect the different ganglia used (thoracic compared to trigeminal), the longer exposure time used by Gilden et al (1987), or even low level virus reactivation. Meanwhile, the rare detection of VZV in neurons is supported by the low VZV burden (6-31 copies in $10^{5}$ human ganglionic cells) determined by quantitative PCR (Mahalingam et al, 1993).

Later Dueland et al (1995) amplified VZV in situ followed by ISH with nonradioactive digoxigenin labeled DNA probes, and found VZV DNA exclusively in the cytoplasm of neurons of trigeminal ganglia from five of seven subjects. While their findings support the studies by Hyman et al (1983) and Gilden et al (1987), the detection of VZV DNA in the cytoplasm of neurons was unexpected.

Localization of DNA in cytoplasm might be due to the leakage of small product (250 bp) amplified DNA from the nucleus, particularly since a larger amplification product ( $640 \mathrm{bp}$ ) of a cellular gene (tubulin) was localized within the nucleus of all cells. Although amplification in situ followed by ISH is a powerful technique, the PCR can be affected by the quality of the ganglia, the fixative, the 


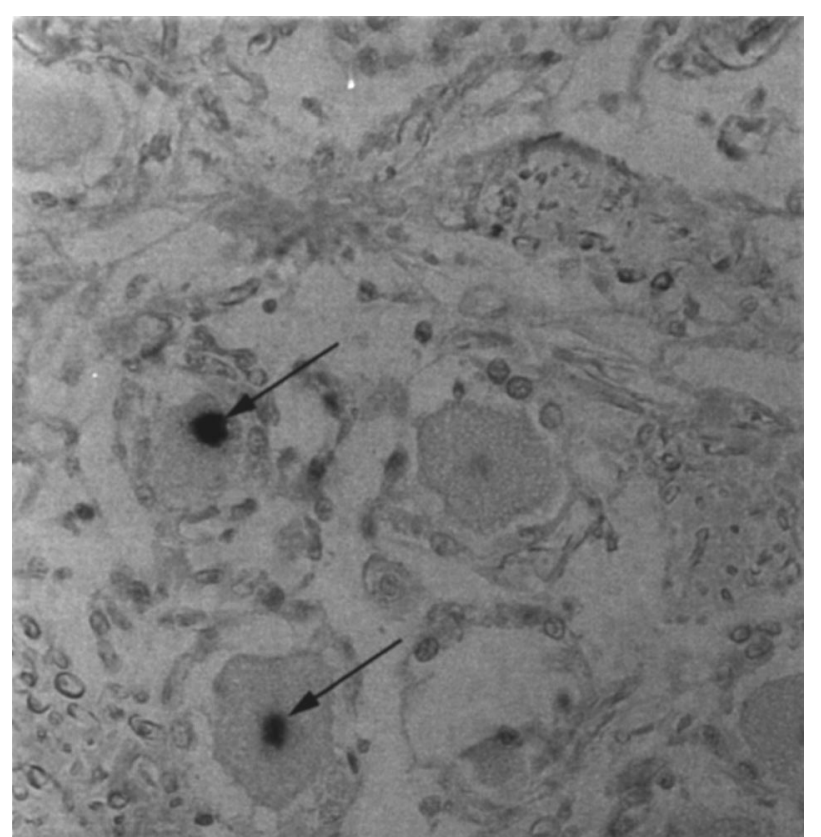

Figure 1 Detection of VZV DNA (gene 29) using in situ-PCR amplification in a normal adult human trigeminal ganglion. Amplified VZV DNA sequences (arrows) are shown in the nuclei of two neurons. $(\times 570)$.

pretreatment protocol, the size of the amplified segment, and any leakage outside the target cell. Thus, even with rigorous controls, results must be interpreted cautiously.

In contrast to all the studies described above, there are two reports of VZV in perineuronal satellite cells (Croen et al, 1988; Meier et al, 1993). Using ${ }^{35}$ S-labeled riboprobes, Croen et al (1988) detected VZV RNA corresponding to VZV genes 4, 29,62 and 63 in $0.01-0.15 \%$ of non-neuronal cells in trigeminal ganglia from 15 of 30 individuals after $4-7$ days of exposure. Using ${ }^{35} \mathrm{~S}$-labeled riboprobes specific for VZV genes 28, 29 and 62, Meier et al (1993) found VZV RNA with VZV gene 29- and 62specific probes in non-neuronal cells of multiple human trigeminal ganglia. In the same study, using ${ }^{35} \mathrm{~S}$-labeled riboprobes specific for VZV genes 4, 10, 28, 29, 61 and 62 in Northern blotting, they detected only VZV genes 29 and 62, but not VZV gene 4, thus failing to confirm their earlier detection by ISH of VZV gene 4 during latency.

Further complicating these issues is the report by Lungu et al (1995) that VZV DNA was present in both neurons and non-neuronal cells of latently infected human ganglia. They examined ten ganglia from two adults by ISH with a fluorescein-labeled oligonucleotide probe and amplified the signal with an anti-fluorescein antibody conjugated to alkaline phosphatase. A VZV-specific signal was detected in $5-30 \%$ of both neurons and non-neuronal cells. The abundance of VZV-positive cells reported by these authors contradicts not only the smaller numbers described in earlier ISH experiments (Hyman et al, 1983; Croen et al, 1988), but also the small amount of VZV detected by quantitative PCR in latently infected human ganglia (Mahalingam et al, 1993). Recently, Lungu et al (1998) have also shown the presence of translation products of VZV ORFs 4, 21, 29, 62 and 63 predominantly in the cytoplasm of neurons of latently infected human ganglia.

Although zoster does not develop in any animals after experimental infection with VZV, they will produce antibody (Wroblewska et al, 1993) and VZV can be found in ganglia. For example, SadzotDelvaux et al (1990) infected rats with VZV, and removed ganglia 1-9 months later. Using either radioactively $\left({ }^{35} S\right)$ or nonradioactively (biotin) labeled DNA probes representing the entire VZV genome and anti-VZV antibodies, VZV nucleic acids (DNA and RNA) and proteins were found exclusively in neurons of dissociated dorsal root ganglion cells in culture. The detection of VZVspecific proteins suggests virus reactivation, and most importantly, from neurons.

Using the same rat model, antibodies raised against in vitro-expressed VZV gene 63 detected the expression of the viral protein in neurons (Debrus et al, 1995). VZV gene 63 protein was also found exclusively in the cytoplasm of neurons in 10 of 52 latently infected human trigeminal and thoracic ganglia from 6 of 19 individuals (Mahalingam et al, 1996). Although none of the subjects whose ganglia were studied had any recent apparent VZV infection, low level virus reactivation is always possible. Even so, virus-specific protein was detected only in neurons. In contrast, in ganglia examined 33 days after experimental infection of mice with VZV, VZV RNA transcribed from the EcoRI-C and D fragments was found mostly in nonneuronal cells and occasionally in neurons (Wroblewska et al, 1993). Table 1 summarizes results of human and animal models of VZV latency.

\section{Conclusion}

Despite considerable work by numerous laboratories, the exact intracellular location of latent VZV in human ganglia is still unclear. Problems are both clinical and technical. First, studies of human autopsy material may be confounded by the risk of low level subclinical virus reactivation. This issue may be resolved by identification of different VZV transcripts. For example, the detection of VZV early genes, in the absence of late virus gene transcription, is a hallmark of latency, and indicates probable lack of reactivation. Second, many ISH studies used radioactive probes, and the results were dependent upon the very subjective observation of grains, often very few, which may have 
Table 1 Ganglionic cells latently infected with varicella zoster virus

\begin{tabular}{|c|c|c|c|c|}
\hline Species & Neurons & $\begin{array}{c}\text { Cell-type } \\
\text { Non-neuronal cells }\end{array}$ & Technique & Reference \\
\hline Human & + & & ISH & Hyman et al, 1983 \\
\hline Human & + & & ISH & Tenser and Hyman, 1987 \\
\hline Human & + & & ISH & Gilden et al, 1987 \\
\hline Human & & + & ISH & Croen et al, 1988 \\
\hline Human & & + & ISH & Meier et al, 1993 \\
\hline Human & + & & PCR - ISH & Dueland et al, 1995 \\
\hline Human & + & + & ISH & Lungu et al, 1995 \\
\hline Human & + & & $\mathrm{IHC}^{*}$ & Mahaligam et al, 1996 \\
\hline Human & + & rare & PCR - ISH & Kennedy et al, 1998 \\
\hline Human & + & & IHC & Lungu et al, 1998 \\
\hline Rat & + & & ISH & Sadzot-Delvaux et al, 1990 \\
\hline Rat & + & & IHC & Debrus et al, 1995 \\
\hline Mouse & + & + & ISH & Wroblewska et al, 1993 \\
\hline
\end{tabular}

*Immunohistochemistry.

bound nonspecifically to cells. A color indicator system applied after hybridization of a nonradioactive probe to latently infected ganglia may pinpoint the cell containing a specific viral DNA or its transcript. Third, the low abundance of VZV in latently infected ganglia has not allowed its detection consistently by ISH. It is becoming increasingly evident that direct incorporation of digoxigenin or biotin-labeled nucleotide in the PCR reaction or a PCR step to amplify the VZV gene of interest followed by ISH is necessary. Latent VZV transcripts can also be amplified in individual ganglionic cells either by direct RT-PCR or combined with in situ transcription (Van Gelder et al, 1990). Another in vitro technique to identify cells latently infected with VZV would isolate fresh ganglionic cells and sort them by size selection, by panning or by attachment to neuron or other cell surface-specific antibody; after enrichment, the various cell populations can be analyzed for virus by ISH, PCR-ISH, RT-PCR-ISH, or PCR alone.

Finally, simian varicella virus (SVV) infection of primates parallels VZV infection of humans (Mahalingam et al, 1991). An advantage of the SVV primate infection model is that healthy latently infected ganglia can be removed from anesthetized monkeys just before necropsy and before reactivation becomes an issue. An additional advantage of

\section{References}

Croen KD, Ostrove JM, Dragovic LJ, Straus SE (1988). Patterns of gene expression and sites of latency in human nerve ganglia are different for varicella-zoster and herpes simplex viruses. Proc Natl Acad Sci USA 85: $9773-9777$.

Debrus S, Sadzot-Delvaux C, Nikkels AF, Piette J, Rentier B (1995). Varicella-zoster virus gene 63 encodes an immediate-early protein that is abundantly expressed during latency. J Virol 69: 3240-3245. the primate system is that an expressible marker can be incorporated into the SVV genome which will readily localize the cell containing latent virus. Although the VZV genome can similarly be manipulated, experimental infection with modified virus is not possible in humans.

Overall, the careful hard work of numerous laboratories around the world which analyze VZV latency have increasingly indicated that neurons are the primary cell infected during latency in ganglia. However, the exact location within neurons and a more accurate abundance of latent virus remain to be determined. Such important questions have considerable practical interest since strategies designed to prevent virus reactivation and subsequent neurologic disease is dependent on a more complete understanding of the molecular basis of VZV latency.

\section{Acknowledgments}

Supported in part by Public Health Service Grants from the National Institutes of Health: AG 06127 and NS 32623 (R Mahalingam and DH Gilden), and The Wellcome Trust (PGE Kennedy). We thank Mary Devlin for editorial review, and Cathy Allen for preparing the manuscript.
Dueland AN, Ranneberg-Nilsen T, Degre M (1995). Detection of latent varicella zoster virus DNA and human gene sequences in human trigeminal ganglia by in situ amplification combined with in situ hybridization. Arch Virol 140: 2055-2066.

Gilden DH, Rozenman Y, Murray R, Devlin M, Vafai A (1987). Detection of varicella-zoster virus nucleic acid in neurons of normal human thoracic ganglia. Ann Neurol 22: 377-380. 
Hyman RW, Ecker JR, Tenser RB (1983). Varicella-zoster virus RNA in human trigeminal ganglia. Lancet 2: 814-816.

Kennedy PGE, Grinfeld E, Gow JW (1998). Latent varicella-zoster virus is located predominantly in neurons in human trigeminal ganglia. Proc Natl Acad Sci USA 95: 4658-4662.

Lungu O, Annunziato P, Gershon A, Staugaitias SM, Josefson D, LaRussa P, Silverstein SJ (1995). Reactivated and latent varicella-zoster virus in human dorsal root ganglia. Proc Natl Acad Sci USA 92: 10980-10984.

Lungu O, Panagiotidis CA, Annunziato PW, Gershon AA, Silverstein SJ (1998). Aberrant intracellular localization of varicella-zoster virus regulatory proteins during latency. Proc Natl Acad Sci USA 95: 70807085 .

Mahalingam R, Smith D, Wellish M, Wolf W, Dueland AN, Cohrs R, Soike K, Gilden DH (1991). Simian varicella virus DNA in dorsal root ganglia. Proc Natl Acad Sci USA 88: $2750-2752$.

Mahalingam R, Wellish M, Lederer D, Forghani B, Cohrs R, Gilden DH (1993). Quantitation of latent varicellazoster virus DNA in human trigeminal ganglia by polymerase chain reaction. J Virol 67: 2381-2384.
Mahalingam R, Wellish M, Cohrs R, Debrus S, Piette J, Rentier B, Gilden DH (1996). Expression of protein encoded by varicella-zoster virus open reading frame 63 in latently infected human ganglionic neurons. Proc Natl Acad Sci USA 93: 2122-2124.

Meier JL, Holman RP, Croen KD, Smialek JE, Straus SE (1993). Varicella-zoster virus transcription in human trigeminal ganglia. Virology 193: $193-200$.

Sadzot-Delvaux C, Merville-Louis M-P, Delree P, Marc P, Piette J, Moonen G, Rentier B (1990). An in vivo model of varicella-zoster virus latent infection of dorsal root ganglia. J Neurosci Res 26: 83-89.

Tenser RB, Hyman RW (1987). Latent herpesvirus infections of neurons in guinea pigs and humans. Yale J Biol Med 60: 159-167.

Van Gelder RN, von Zastrow E, Yool A, Dement WC, Barchas JD, Eberwine JH (1990). Amplified RNA synthesized from limited quantities of heterogeneous cDNA. Proc Natl Acad Sci USA 87: 1663-1667.

Wroblewska Z, Valyi-Nagy T, Otte J, Dillner A, Jackson A, Sole DP, Fraser NW (1993). A mouse model for varicella-zoster virus latency. Microb Path 15: 141151. 